\title{
UREĐENJA OBAVEZNOG PRIMJERKA ELEKTRONSKE GRAĐE
}

\author{
Lejla Hajdarpašić \\ Odsjek za komparativnu književnost i bibliotekarstvo, Katedra za bibliotekarstvo, Filozofski fakultet Univerziteta u \\ Sarajevu, Sarajevo, Bosna i Hercegovina \\ Department of Comparative Literature and Library Sciences, Department of Library Sciences, Faculty of Philosophy, \\ University of Sarajevo, Sarajevo, Bosnia and Herzegovina \\ lejla.hajdarpasic@ff.unsa.ba
}

\begin{abstract}
Sažetak
Proširenje obuhvata obaveznog primjerka, odnosno njegova prilagodba digitalnom univerzumu, prepoznalo se kao konstruktivno rješenje prikupljanja, očuvanja te omogućavanja pristupa dematerijaliziranim objektima nacionalne bibliografske kontrole. S tim u vezi, referirajući se na rezultate relevantnih i aktualnih istraživanja o uređenju obaveznog primjerka elektronske građe na međunarodnom nivou, ovaj rad kao pretpostavku uspješnosti i stabilnosti nacionalne bibliografske kontrole u mijenjajućem okruženju, a u zemljama koje imaju tradiciju zakona o obaveznom primjerku i kojima predstoji započeti s procesom prikupljanja i očuvanja dematerijaliziranih objekata nacionalne bibliografske kontrole, ukazuje na potrebu redefiniranja postojećih nacionalnih zakona o obaveznom primjerku. $U$ radu se naglašavaju prednosti takvoga pristupa te se iznosi zaključak da planiranje, tj. uređenje nacionalne bibliografske kontrole, koje je u znaku zagovaranja i osvještavanja značaja zakona o obaveznom primjerku te njegovanja specifične tradicije nacionalne bibliografske kontrole, a prevashodno informacijskih potreba korisnika, treba paralelno pratiti i planiranje redefiniranja nacionalnih zakona o autorskim pravima i drugih srodnih zakona, koji nerijetko parališu temeljne vrijednosti obaveznog primjerka u smislu da otežavaju neometan pristup građi prispjeloj po principu obaveznog primjerka.
\end{abstract}

Ključne riječi: obavezni primjerak, nacionalna bibliografska kontrola, Univerzalna bibliografska kontrola

\section{Uvodna razmatranja}

Kada je 70-tih godina prošlog stoljeća Liebaers zamislio program Univerzalne bibliografske kontrole kao "intelektualnu konstrukciju, usmjerenu na stvarnost, na poznate probleme, $\mathrm{i}$ istovremeno kao maštovito traženje budućih područja potrebe" (Anderson 2000, 210), zasigurno da nije mogao anticipirati izazove s kojima će se ovaj reprezentativni program suočiti s kraja 20. i početkom 21. stoljeća. Velike promjene u načinima komunikacije i kreacije znanja, brzi razvoj tehnologija, pojava World Wide Weba te posljedično tome i dematerijaliziranih objekata nacionalne bibliografske kontrole, otvorili su niz pitanja na koje je program nacionalne, odnosno Univerzalne bibliografske kontrole morao ponuditi odgovarajuće odgovore. U tom procesu zakoni o obaveznom primjerku opravdano su okupirali pažnju međunarodne akademske / stručne bibliotečke zajednice koja je upozorila na potrebu redefiniranja takvih legislativa, s ciljem iznalaženja konstruktivnih rješenja u pogledu prikupljanja, očuvanja i omo- gućavanja pristupa dematerijaliziranim objektima nacionalne bibliografske kontrole. Ipak, koliko se u refleksijama, diskusijama o obaveznom primjerku, implementacijama preoblikovanih zakona o obaveznom primjerku digitalne građe posljednje dvije dekade uspješno vodilo računa o temeljnim vrijednostima obaveznog primjerka, misleći pritom najprije na njegovu korisničku dimenziju? Savremene prakse i trendovi, uz rijetke izuzetke, upućuju na zaključak da uprkos brojnim naporima nacionalnih bibliografskih centara, orijentiranih ka zagovaranju svih važnih zadataka obaveznog primjerka, svjedočimo svojevrsnom digitalnom zidu postavljenom između korisnika i raznolike nacionalno relevantne digitalne građe prikupljene po principu obaveznog primjerka. U takvim okolnostima, tj. sa takvim saznanjima, u zemljama kojima predstoji proširenje obuhvata obaveznog primjerka i na elektronsku građu, započinjanje s procesom arhiviranja sadržaja s weba, a u koje se ubraja i Bosna i Hercegovina, neupitno da se donošenju strategija prikupljanja, 
očuvanja i omogućavanja pristupa digitalnoj baštini mora pristupiti krajnje oprezno, kritički promišljajući o planiranju nacionalne bibliografske kontrole, uvažavajući pritom sve bibliografske specifičnosti zemlje, njene tradicije, postojeće zakonske propise $\mathrm{i}$ iskustva u pogledu uspostave nacionalne bibliografske kontrole, a još važnije korisnike i njihove raznolike informacijske potrebe.

\section{Uređenja obaveznog primjerka elektronske građe na međunarodnom nivou}

Preporuke Međunarodne konferencije o nacionalnim bibliografskim službama, održane u Kopenhagenu 1998. godine, Obavezni primjerak elektronskih publikacija pripremljen od Radne grupe CDNL iz 1996. godine, Međunarodne smjernice za izradu zakona o obaveznom primjerku autora Julesa Larivierea iz 2000. godine (revidirano izdanje UNESCO-vih Smjernica za izradu zakona o obaveznom primjerku autora Jeana Lunna, 1981. godina), Smjernice o bibliotečkom zakonodavstvu i politici u Europi koje potpisuju Vijeće Europe i EBLIDA iz 2000. godine, zajednička izjave IFLA-e i IPA-e iz 2002. godine, UNESCO-va Povelja o očuvanju digitalne baštine iz 2003. godine, UNESCO-ve Smjernice za očuvanje digitalne baštine također iz 2003. godine, Smjernice za nacionalne bibliografije u elektronskom dobu iz 2008. godine, Izjava IFLAe o obaveznom primjerku iz 2011. godine, UNESCO/PERSIST smjernice za odabir digitalne baštine za dugoročno očuvanje iz 2016. godine, samo su neki od relevantnih događaja, dokumenata, izjava koji su posljednjih desetljeća podsjetili na potrebu proširenja obuhvata obaveznog primjerka na digitalnu građu, tematizirajući pritom različite aspekte njegove implementacije.

S tim u vezi, primjerice UNESCO-ve smjernice naglašavaju da bilo koja vrsta građe, neovisno o formatu, sve dok je javno dostupna i objavljena u više primjeraka, treba biti predmetom obaveznog primjerka, to jest da samo djelotvoran zakon o obaveznom primjerku može građanima i istraživačima $u$ zemlji i inostranstvu garantirati pristup svoj objavljenoj građi u pojedinoj zemlji (Larivière 2000).

U praksi je pomenuta preokupacija obaveznim primjerkom, odnosno prijeko potrebnim redefiniranjem praksi nacionalnih biblioteka oko uspostave nacionalne bibliografske kontrole $\mathrm{u}$ digitalnom okruženju, te posljedično tome izrade nacionalne bibliografije, bila orijentirana ponajviše u pravcu proširenja obuhvata nacionalnih zakona o obaveznom primjerku na elektronsku građu. Uprkos prisutnim ponekim razlikama $u$ definiranju obuhvata obaveznog primjerka elektronske građe, brojne nacionalne biblioteke su uložile velike napore i stekle pažnje vrijedna iskustva u prikupljanju, obradi, po- hrani digitalnog kulturnog naslijeđa u materijalnom obliku te u procesima sveobuhvatnog i/ili selektivnog arhiviranja sadržaja sa weba i tome slično, zahvaljujući uređenim legislativama, a u rijetkim slučajevima oslanjajući se na (prošireni) dobrovoljni obavezni primjerak elektronske građe.

Konačno, kada je prikupljanje i nacionalno relevantne štampane građe u pitanju, međunarodno istraživanje o bibliografskoj kontroli i nacionalnim bibliografijama, koje je realizirao Robert P. Holley davne 1996. godine, a kojim su obuhvaćene 64 zemlje, otkrilo je da većina nacionalnih bibliografskih centara $(92,2 \%)$ štampanu građu prikuplja po principu obaveznog primjerka, odnosno da te zemlje imaju nacionalne zakone o obaveznom primjerku, različitoga obuhvata (Holley 1998, 15). Kasnije, slične trendove je potvrdilo i istraživanje Knutsen iz 2001. godine koje je, na temelju pristigla 52 odgovora, pokazalo da 50 zemalja ima nacionalne zakone o obaveznom primjerku štampane građe, različitog obuhvata (Knutsen 2001), a i posljednji izvještaj o zakonima o obaveznom primjerku u odabranim jurisdikcijama iz 2017. godine, koji izrađuje The Law Library of Congress, Global Legal Research Center, a koji donosi podatke za čak 131 zemlju, otkriva da je, izuzev 13 zemalja koje imaju praksu dobrovoljnog depozita ili kod kojih se nisu mogle pronaći informacije o sistemu depozita građe, deponovanje štampanih knjiga zakonski regulirana praksa (Mandatory Deposit Laws in Selected Jurisdictions, 2017).

Nekoliko istraživanja o uređenju obaveznog primjerka na međunarodnom nivou posvjedočilo je da su u praksama prikupljanja i očuvanja digitalne građe od nacionalnog značaja dominantni trendovi preoblikovanja, odnosno proširenja nacionalnih zakona o obaveznom primjerku. U tom smislu, IFLA-ino istraživanje o uključivanju elektronske građe (daljinski i mjesno dostupne) u nacionalne bibliografije iz 2005. godine, kojim su obuhvaćene 32 institucije, a koje donosi informacije o obuhvatu obaveznog primjerka $\mathrm{u}$ anketiranim zemljama, kao i njihovim aktivnostima arhiviranja, pokazalo je da 30 anketiranih nacionalnih bibliografskih centara ima zakon o obaveznom primjerku, dok su 22 izjavila da planiraju proširiti obuhvat obaveznog primjerka na elektronsku građu (Wiggins 2005).

Već 2009. godine u istraživanju, koje potpisuje British Library, a kojim su obuhvaćene 34 zemlje, donose se podaci da su u čak 26 zemalja zakoni o obaveznom primjerku implementirani (za mjesno dostupne publikacije), a tada je već 12 biblioteka imalo zakonske ovlasti za prikupljanje mrežnih publikacija, slobodno dostupnih i komercijalnih (International Survey on Electronic Legal Deposit, 2010).

Drugo istraživanje British Library, realizirano 2011. godine sa većim obuhvatom, donoseći podatke za 
55 biblioteka detektovalo je da 40 posto anketiranih biblioteka ima uređenu legislativu arhiviranja sadržaja, kojom prilikom je čak 30 izvijestilo da planiraju revidirati zakonske prakse $u$ tom smislu (British Library International Survey of E-Legal Deposit, 2011).

2015. godine autori Zarndt, Carner i McCain prezentirali su rezultate Međunarodnog istraživanja o politikama i praksama "digitalno rođenog" obaveznog primjerka, kojim je obuhvaćeno 20 biblioteka, iznova potvrđujući da se "zakoni o obaveznom primjerku uvelike razlikuju od zemlje do zemlje. Dok neke zemlje, poput Švedske i Danske, već nekoliko godina prikupljaju digitalne sadržaje, u mnogim zemljama digitalna komponenta u zakonima o obaveznom primjerku nije prisutna" (Zarndt et al. 2015).

Jedno od posljednjih istraživanja o obaveznom primjerku elektronske građe iz 2017. godine, Istraživanje o politikama i praksama obaveznog primjerka u nacionalnim bibliotekama, donosi podatke za čak 189 institucija, a 2017. godine autori su prezentirali rezultate istraživanja samo za 31 nacionalnu biblioteku, od kojih je 26 biblioteka izvijestilo da ima zakon o obaveznom primjerku, a 5 biblioteka da nemaju takvu legislativu. Također, 20 anketiranih biblioteka je izvijestilo da je u obuhvat njihovih nacionalnih zakona o obaveznom primjerku uključena i digitalna građa (Zarndt et al. 2017).

Iako temeljem pristiglih odgovora istraživanje konstatuje "spor napredak u ovom području" (Zarndt et al. 2017), ono donosi dokaze o ogromnim naporima nacionalnih bibliografskih centara orijentiranih ka sistemskom prikupljanju i očuvanju digitalne nacionalno relevantne građe, koje idu u pomenutom pravcu favoriziranja legislativa koje uređuju ovu oblast, istovremeno detektujući i neke od nerazriješenih prepreka u radnim procesima nacionalne bibliografske kontrole, u setu kojih kao posebno važne treba izdvojiti probleme pristupa građi prikupljenoj po principu obaveznog primjerka.

S tim u vezi, treba spomenuti da je još Izvještaj Europske komisije o digitalizaciji i mrežnoj pristupačnosti kulturnog materijala te o dugoročnom očuvanju u Europskoj Uniji iz 2010. godine otkrio zabrinjavajuće činjenice unutar evropskog prostora pokazavši da se zbog zaštite autorskih prava pristup obaveznom primjerku različito definira $-u$ pojedinim zemljama taj je pristup omogućen samo u prostorijama biblioteke (npr. Francuska) ili je potpuno ograničen (Second progress report on the digitisation and online accessibility of cultural material and on digital preservation in the European Union, 2010). U aspektima ograničavanja pristupa građi te omogućavanja simultanog pristupa građi određenom broju korisnika, slične izazove je potvrdilo istraživanje British Library iz 2011. godine. Istraživanje o politikama i praksama obaveznog primjer- ka u nacionalnim bibliotekama također je potvrdilo da je pristup obaveznom primjerku digitalne građe $\mathrm{u}$ anketiranim nacionalnim bibliotekama $\mathrm{u}$ velikoj mjeri ograničen. 14 biblioteka je izvijestilo da je pristup sadržajima moguć samo u prostorijama biblioteke ili mrežama koje su kontrolirane od strane biblioteke, 2 biblioteke su izvijestile da je pristup omogućen u prostorijama biblioteke, izvan prostorija biblioteke i na mrežama koje su kontrolirane od strane biblioteke nakon perioda embarga, 5 biblioteka je izvijestilo da je pristup omogućen u prostorijama biblioteke, izvan prostorija biblioteke i na mrežama koje su kontrolirane od strane biblioteke odmah, a ni u jednoj biblioteci sadržaj se ne može besplatno preuzimati (Zarndt et al 2017).

Kada je ova vitalna zadaća obaveznog primjerka u pitanju, neophodno je spomenuti i rijetki istraživački projekt, Digital Library Futures, koji se usredotočio na stvarno korištenje obaveznog primjerka, odnosno utjecaj novog zakona o obaveznom primjerku digitalne građe iz 2013. na akademske depozitarne biblioteke i njihove korisnike u Ujedinjenom Kraljevstvu. Cijeneći da je pomenuti zakon o obaveznom primjerku krajnje neophodan, autori su naglasili da ipak nije u cijelosti realiziran, budući da, između ostalog, "protokoli pristupa građi prikupljenoj po principu obaveznog primjerka ne podržavaju informacijsko ponašanje korisnika i informacijske potrebe korisnika u pogledu korištenja digitalnih zbirki" (Gooding et al. 2018, 5). Zbog pomenutog autori smatraju da je u planiranju i implementaciji zakona o obaveznom primjerku neštampane građe neophodno kontinuirano voditi računa o okviru evaluacije koji je usmjeren na korisnika, a u tom smislu donose pažnje vrijedan prijedlog okvira koji je temeljen na sljedećih pet načela: 1. Dugoročnu korist od zakona o obaveznom primjerku neštampane građe (dalje u tekstu NPLD, engl. Non-Print Legal Deposit) imaju korisnici, a ne izdavači ili biblioteke. Stoga je potrebno procijeniti NPLD u odnosu na šire potrebe korisnika, čak i ako se te potrebe ne uočavaju odmah, kroz kratkoročne izmjene u uređenju pristupa građi. 2. Raznolikost digitalnih medija odražava velike promjene u razmjeni informacija, društvu, bibliotekama i istraživačkim zajednicama, što zahtijeva ponovno vrednovanje pretpostavke da su štampani mediji najkorisnija polazna tačka za definiranje protokola pristupa. 3. Izdavači imaju pravo zaštititi svoje komercijalne legitimne interese, što je razlog neliberalizacije pristupa građi. Međutim, značaj otvorenog pristupa, rezultirajući pomaci u pravima intelektualnog vlasništva, ne mogu se zanemariti bez kršenja namjera autora da omoguće širi pristup. 4. Bibliotekama se mora omogućiti da poduzimaju aktivnosti kojima mogu odgovoriti na novonastala informacijska ponašanja, uključujući one aktivnosti koje su povezane s digitalnim oču- 
vanjem velikih razmjera. Te bi se aktivnosti trebale temeljiti na evidentiranim trendovima u ponašanju i potrebama korisnika i usredotočiti na to da zbirke budu dugoročno dostupne, upotrebljive i značajne korisnicima. 5. Prva četiri načela zahtijevaju kontinuiranu saradnju između biblioteka, izdavača i korisničkih grupa. Konkretno, biblioteke i istraživači trebaju usko surađivati na promovisanju i razumijevanju jedinstvenosti i vrijednosti zbirki obaveznog primjerka neštampane građe i povećanju svijesti o promjenama u naučnim istraživanjima (Gooding et al. 2018, 29-30).

\section{Ka planiranju bibliografske kontrole elektronske građe}

Naprijed pomenuti rezultati istraživanja svjedoče $u$ prilog tome da favoriziranje preoblikovanja nacionalnih zakona o obaveznom primjerku jeste dominatna, ali nimalo slučajna međunarodna praksa. U tematiziranim zemljama, prednost se daje revidiranju takvih nacionalnih zakonskih propisa, poštujući time tradicije oko uspostave nacionalne bibliografske kontrole, reprezentativno iskustvo nacionalnih bibliografskih centara $\mathrm{u}$ tom procesu, navike izdavačke zajednice u pogledu razumijevanja i poštivanja zakona o obaveznom primjerku, i najvažnije, povjerenje koje je godinama građeno između izdavačke i bibliotečke zajednice u tom smislu. Nesumnjivo su tome doprinijele međunarodne proaktivne reakcije koje su se pojavile u formi smjernica, preporuka, podrške IFLA-e, UNESCO-a i drugih relevantnih tijela, koja su promovirala održivost temeljnih vrijednosti obaveznog primjerka i u digitalnom okruženju, ali jednako tako i kontekst političkih, ekonomskih, društvenih te tehničkih pitanja (Gibby, Brazier, 2012) kroz koja treba "čitati" vrijednosti obaveznog primjerka.

Zemlje koje planiraju osavremeniti prakse nacionalne bibliografske kontrole, u velikoj su prednosti kada se u uzme u obzir progres $\mathrm{i}$ iskustvo međunarodne bibliotečke zajednice u uređenju obaveznog primjerka digitalne građe, s napomenom da takve zemlje svejedno prevashodno trebaju doprinositi kontekstu prilagođene strategije jačanja nacionalne bibliografske kontrole, odnosno promišljati ove neophodne iskorake u skladu sa vlastitim iskustvima i specifičnostima bibliotečko-informacijske infrastrukture.

U tom smislu, uspostavljanje dobrovoljnog obaveznog primjerka elektronske građe kao dugoročno rješenje prikupljanja i očuvanja nacionalno relevantne elektronske građe, u zemljama koje imaju takve planove, a već baštine nacionalne zakone o obaveznom primjerku, kakva je Bosna i Hercegovina, može biti kontraproduktivno. Implementacija obaveznog primjerka elektronske građe iziskuje na- pore u kontekstu definiranja prepreka koje se mogu pojaviti u svim radnim procesima nacionalne bibliografske kontrole, identifikacije, selekcije, obrade, pohrane i omogućavanja pristupa građi, uključujući brojna tehnička pitanja koje prikupljanje građe u materijalnom obliku podrazumijeva, odnosno arhiviranje mrežnih publikacija. Budući da se u tim zahtjevnim iskoracima, upravo proširenjem obuhvata postojećih nacionalnih zakona o obaveznom primjerku, može kreirati okruženje u kojem vrijednosti obaveznog primjerka mogu doći do potpunog izražaja, kao važan korak ka krajnje kompleksnom planiranju, odnosno osavremenjivanju praksi nacionalne bibliografske kontrole, a u zemljama koje već baštine tradiciju takvih zakona, treba dakle prepoznati prilagođavanje legislativa digitalnom kulturnom naslijeđu. Rijetke se zemlje u bibliografskom praćenju digitalne građe uspješno oslanjaju na dobrovoljni obavezni primjerak digitalne građe (npr. Nizozemska), ali ipak, tamo gdje postoje, najprije $\mathrm{u}$ proširenjima nacionalnih zakona o obaveznom primjerku, treba promišljati mogućnosti razvoja i uspješnosti nacionalne bibliografske kontrole. Uspostavljanje dobrovoljnog obaveznog primjerka elektronske građe iziskuje značajne napore i saradnju u kontekstu definiranja obuhvata dobrovoljnog obaveznog primjerka zbog moguće problematike uređenja pristupa deponovanoj građi, kao i rizika odustajanja od sporazuma. Dobrovoljno dostavljanje građe, kako to uostalom i IPA primjećuje, može biti "korisno za identifikaciju i ispravljanje nedostataka" (Digital Legal Deposit, 2014) u procesima upravljanja elektronskom građom.

Međunarodna iskustva svjedoče da revidirane legislative nužno trebaju odražavati sve vrijednosti obaveznog primjerka, posebno afirmirajući njegovu korisničku dimenziju, koja je pod snažnim utjecajem nacionalnih zakona o autorskom pravu i drugim srodnim pravima. U tom smislu, ne iznenađuje što je prateći donekle nezadovoljavajuće rezultate naprijed pomenutog istraživanja o uređenju obaveznog primjerka elektronske građe na međunarodnom nivou, koje je realizirala British Library, CDNL (Conference of Directors of National Libraries) već 2012. godine predložila, donekle u literaturi zanemareni, a izuzetno koristan, set materijala za zagovaranje obaveznog primjerka elektronske građe, u kojima ne zanemaruje korisničku dimenziju obaveznog primjerka u ključnim predloženim principima i tačkama zagovaranja: “...prikupljanjem, evidentiranjem i očuvanjem građe objavljene u zemlji, obavezni primjerak svakom građaninu garantira pristup nacionalnoj baštini...; ...podupire konkurentnost, kreativnost, izvrsnost u istraživanju, obrazovanju i učenju, te na taj način doprinosi ekonomskom razvoju i kulturnom blagostanju; ... garantira građanima $\mathrm{i}$ istraživačima diljem svijeta 
pristup svoj objavljenoj građi u pojedinoj zemlji" (E-Legal Deposit Advocacy Pack, 2012).

Konačno, i Smjernice o bibliotečkom zakonodavstvu i politici u Evropi koje su sačinili Vijeće Evrope i EBLIDA, kao jedan od ciljeva obaveznog primjerka prepoznaju upravo omogućavanje pristupa pohranjenim publikacijama pojašnjavajući da revidiranje obaveznog primjerka "zahtijeva izgradnju mosta između zakona o obaveznom primjerku te zakona koji reguliraju autorska prava, a koji trebaju osigurati pristup deponovanoj elektronskoj građi i ponuditi razumnu naknadu nositeljima autorskih prava" (Guidelines on Library Legislation and Policy in Europe. Council of Europe / EBLIDA, 2000). Svakako da se u ovom kontekstu ne mogu zanemariti ni prava korisnika $\mathrm{s}$ invaliditetom na pristup informacijama, zagarantovana u Konvencija o pravima osoba s invaliditetom. U izvještaju Od boljeg do potpunog pristupa građi za osobe koje ne mogu čitati crni tisak, sačinjenom za Komisiju za pravne poslove Evropskog parlamenta, obavezni primjerak je prepoznat upravo kao "posredno" rješenje u pogledu omogućavanja pristupa sadržajima osobama koje ne mogu čitati crni tisak (Calvo, 2009).

Da u planiranju nacionalne bibliografske kontrole nad digitalnom građom naročito problematika pristupa građi prikupljenoj po principu obaveznog primjerka iziskuje ogromne napore, posvjedočio je i aktualni izvještaj Obavezni primjerak digitalne građe u odabranim jurisdikcijama iz 2018. godine, koji je sačinio The Law Library of Congress, Global Legal Research Center, a u koji su uključene prakse 15 zemalja, tj. njihova pažnje vrijedna iskustva u pogledu implementacije obaveznog primjerka digitalne građe. Izvještaj je pokazao da su u odabranim zemljama pristupi daljinski i mrežno dostupnoj građi različito definirani, primjerice, u Australiji izdavači mogu zatražiti embargo na period od 12 mjeseci za knjige, partiture i karte ili pak period od šest mjeseci za časopise, magazine (Digital Legal Deposit in Selected Jurisdictions, 2018, 12), LAC nudi mogućnost izdavačima da sami definiraju tip pristupa, otvoreni pristup ili ograničeni koji onemogućava printanje, preuzimanje ili prenos podataka sa LACovih terminala (Digital Legal Deposit in Selected Jurisdictions, 2018, 18). Budući da zakonski propisi nerijetko ne idu u korist omogućavanju neometanog pristupa građi prispjeloj po principu obaveznog primjerka, neophodno je dakle u procesima izmjena nacionalnih zakona o obaveznom primjerku intenzivirati saradnju sa zakonodavnim tijelima, izdavačkom zajednicom, autorima, u aspektu koji se tiče liberalnijeg pristupa zbirkama obaveznog primjerka. Saradnja u pogledu harmonizacije legislativa o obaveznom primjerku i autorskim pravima te drugim srodnim pravima izuzetno je važna, posebice u savremenom okruženju koje karakteriziraju sve prisutnije inicijative otvorenog pristupa, orijentiranosti ka konceptu otvorene nauke te inicijative arhiviranja koje koegzistiraju sa naporima nacionalnih biblioteka usmjerenim ka sveobuhvatnom i/ili selektivnom arhiviranju mrežnih publikacija, a kojima brojne institucije i organizacije pristupaju različito, u povećanom obimu. U tom smislu i Holley donosi nimalo ugodno upozorenje: "Savršenstvo je izmijenjeno u korisnost... 'Veliki podaci' postali su jedan od najvećih trendova. 'Mali podaci', uključujući Univerzalnu bibliografsku kontrolu, počeli su se smatrati staromodnim, čak nepodesnim konceptom" (Holley 2014). U takvim okolnostima neophodno je potvrditi značaj nacionalne i posljedično tome Univerzalne bibliografske kontrole, obaveznog primjerka i njegove korisničke funkcije, konačno, ulogu nacionalnih biblioteka u razvijanju strategija, politika otvorenog pristupa, jer budući da se "otvoreni pristup u osnovi odnosi na dostupnost nacionalnih naučnih publikacija, vrlo dobro se uklapa u druge zadatke nacionalnih biblioteka $\mathrm{u}$ digitalnom okruženju, kakve su nacionalne bibliografske usluge, upravljanje obaveznim primjerkom digitalne građe i omogućavanje pristupa digitalnim dokumentima" (Hagerlid 2011).

\section{Zaključna razmatranja}

Neprilagođost obaveznog primjerka specifičnostima nacionalno relevantne građe koja se pojavljuje $u$ digitalnom obliku ostavlja nepopravljive i nesagledive posljedice u kontekstu kompletnosti nacionalnih zbirki i posljedično tome nacionalnih bibliografija, zahtijevajući u tom smislu neodložno preoblikovanje praksi nacionalnih bibliografskih centara oko uspostave nacionalne bibliografske kontrole. Iako su u radu navedena međunarodna iskustva pokazala da su zakonska rješenja na kojima se temelji nacionalna bibliografska kontrola nerijetko spora $\mathrm{i}$ krajnje zahtjevna, savremeno dinamično informacijsko okruženje sa svim svojim specifičnostima i izazovima zahtijeva upravo donošenje stabilnih, na legislativi temeljenih strategija uređenja $\mathrm{i}$ jačanja nacionalne bibliografske kontrole u 21. stoljeću. S ciljem planiranja i donošenja nacionalnih zakonskih propisa koji mogu omogućiti višestruke prednosti obaveznog primjerka i u digitalnom okruženju, u uspostavljanju dijaloga sa zakonodavnim tijelima i održavanju kontinuiranih konsultacija sa izdavačkom zajednicom, neophodno je, pored arhivističke, naglašavati važniju korisničku funkciju obaveznog primjerka. Drugim riječima, u započinjanju planiranja sistemskog prikupljanja digitalne građe po principu obaveznog primjerka mora se voditi računa o svim radnim procesima nacionalne bibliografske kontrole, od kojih uređenje pristupa zbirkama obaveznog primjerka zahtijeva posebnu pažnju i tijesnu saradnju svih uključenih strana. 


\section{Literatura}

- Alexandrov, Georgi. 2018. "Transformation of Digital Legal Deposit in Terms of Legislation and Public Access" Knygotyra 70. Doi: 10.15388/ Knygotyra.2018.70.11812

- Anderson, Dorothy. 2000. "IFLA's Programme of Universal Bibliographic Control: Origins and Early Years" IFLA Journal 26(3): 209-214

- British Library: International Survey on Electronic Legal Deposit. 2010. CDNL Annual Meeting, Gothenburg, 12 August. http://www.cdnl.info/Legal_Deposit/CDNL_2010_-_BL_international_survey_on_e-Legal_Deposit.pdf. Datum pristupa: 18 . 10. 2019 .

- $\quad$ Brindley, Lynne, "British Library International Survey of E-Legal Deposit 2011: Summary of Findings" CDNL Annual Meeting, Puerto Rico. http:// www.cdnl.info/sites/default/files/docs/2011_legaldeposit_survey_Slides_Aug.pdf. Datum pristupa: 20. 10. 2019.

- $\quad$ Digital Legal Deposit. An IPA Special Report. 2014. https://www.internationalpublishers.org/images/ news/2014/digital-legal-deposit-2014.pdf. Datum pristupa: 9. 10. 2019.

- Digital Legal Deposit in Selected Jurisdictions. 2018. The Law Library of Congress, Global Legal Research Center. https://www.loc.gov/law/help/digital-legal-deposit/digital-legal-deposit.pdf. Datum pristupa: 1. 10. 2019.

- E-Legal Deposit Advocacy Pack [draft]. 2012. Conference of Directors of National Libraries. http:// www.cdnl.info/2012/pdf/Annual\%20Meeting/ Towards_an_advocacy.pdf. Datum pristupa: 21. 10. 2019.

- Gibby, Richard, i Brazier, Caroline. 2012. “Observations on the development of non-print legal deposit in the UK" Library Review 61(5): 362-377.

- Gooding, Paul, Melissa Terras, i Linda Berube. 2019. Towards User-Centric Evaluation of UK Non-Print Legal Deposit: A Digital Library Futures White Paper. http://elegaldeposit.org/documents/18208810/0/DLF+White+Paper/c774b0aa4272-446a-1fad-b56ccb047361. Datum pristupa: 10. 10. 2019.

- Guidelines on Library Legislation and Policy in Europe. 2000. Council of Europe / EBLIDA. http:// www.coe.int $/ \mathrm{t} / \mathrm{dg} 4 /$ cultureheritage/culture/resources/DECS_CULT_POL_book(2000)1_EN.pdf. Datum pristupa: 18. 10. 2019.

- Hagerlid, Jan. 2011. "The role of the national library as a catalyst for an Open Access agenda: the experience in Sweden" Interlending \& Document Supply 39(2). Doi: 10.1108/02641611111138923.

- Holley, Robert P. 1998. "Results of a Survey on Bibliographic Control and National Bibliography" U
Pre-Conference Booklet. Universal Bibliographic Control and International MARC Core Programme (UBCIM) and Division of Bibliographic Control, ICNBS, Copenhagen, 25-27 November. https://archive.ifla.org/ubcim/icnbs/preconf.pdf. Datum pristupa: 20. 10. 2019.

- Holley, Robert P. 2014. "Self-Publishing: A New Challenge for Universal Bibliographic Control." Rad prezentiran na 80th IFLA World Library and Information Congress General Conference and Assembly, Lyon, France. http://digitalcommons. wayne.edu/slisfrp/124. Datum pristupa: 1. 10. 2019.

- Knutsen, Unni. 2001. "Changes in the National Bibliographies, 1996-2001" Rad prezentiran na 67th IFLA Council and General Conference, August 1625. https://files.eric.ed.gov/fulltext/ED459803.pdf. Datum pristupa: 20. 10. 2019.

- Larivière, Jules. 2000. Guidelines for legal deposit legislation. Paris: UNESCO.

- Mandatory Deposit Laws in Selected Jurisdictions: (2017 Update). 2017. The Law Library of Congress, Global Legal Research Center. https://www.loc.gov/ law/help/deposit-laws/mandatory-deposit-laws.pdf. Datum pristupa: 1. 10. 2019.

- Preserving the memory of the world in perpetuity: a joint statement on the archiving and preserving of digital information. 2002. IFLA/IPA Steering group. http://archive.ifla.org/V/press/ifla-ipa02.htm. Datum pristupa: 3. 10. 2019.

- Second progress report on the digitisation and online accessibility of cultural material and on digital preservation in the European Union: Working document. 2010. European Commission, Information Society and Media Directorate-General. http://ec.europa.eu/ information_society/activities/digital_libraries/doc/ recommendation/reports_2010/2010\%20Digitisation\%20report\%20overall.pdf. Datum pristupa: 4. 1. 2019.

- Zarndt, Frederick, Dorothy Carner, i McCain, Edward. 2015. "An International Survey of Born Digital Legal Deposit Policies and Practices" International News Media Conference. https://www.ifla. org/files/assets/clm/publications/13_-_2015_an_international_survey_of_born_digital_legal_deposit_policies_and_practices.pdf. Datum pristupa: 22 . 10. 2019 .

- Zarndt, Frederick, Dorothy Carner, i McCain, Edward. 2017. Born Digital Legal Deposit Policies and Practices IFLA WLIC, Satellite Meeting: Relying on News Media. Long Term Preservation and Perspectives for Our Collective Memory. http:// library.ifla.org/1905/1/S18-2017-zarndt-en.pdf. Datum pristupa: 22. 10. 2019. 
- Wiggins, Beacher. 2005. "IFLA survey on inclusion of electronic resources in national bibliographies." Rad prezentiran na World Library and Information Congress: 71th IFLA General Conference and Council "Libraries - A voyage of discovery", Oslo, Norway. https://archive.ifla.org/IV/ifla71/ papers/177e-Wiggins.pdf. Datum pristupa: 18. 10. 2019.

\title{
E-LEGAL DEPOSIT ARRANGEMENTS
}

\begin{abstract}
The extension of legal deposit, its adaptation to the digital universe, was recognized as a constructive solution for the collection and preservation, as well as the provision of access to dematerialized objects of national bibliographic control. In this regard, by referring to the results of relevant and current international surveys about e-legal deposit arrangements, this paper assumes that the success and stability of national bibliographic control in a changing environment, and in countries that have a tradition of legal deposit legislation and are about to begin with the collection and preservation of the dematerialized national bibliographic control objects, lies in redefinition of existing national legal deposit legislation. The paper emphasizes the advantages of such an approach and concludes that planning and organization of national bibliographic control, that is followed by raising awareness about the importance of the legal deposit, and respecting the specific tradition of national bibliographic control, but primarily information needs of users, should be accompanied with the redefinition of the national copyright laws, and other related laws, which frequently paralyze the core values of the legal deposit in terms of providing access to the legal deposit collections.
\end{abstract}

Keywords: legal deposit of electronic publication, national bibliographic control, Universal bibliographic control 